\title{
The Influence of Multiscale Fillers Reinforcement into Impact Resistance and Energy Absorption Properties of Polyamide 6 and Polypropylene Nanocomposite Structures
}

\author{
Francesco Silva $^{1}$, James Njuguna ${ }^{1 *}$, Sophia Sachse ${ }^{1}$, Krzysztof Pielichowski ${ }^{2}$ Agnieszka \\ Leszczynska $^{2}$ and Marco Giacomelli ${ }^{3}$ \\ ${ }^{1}$ Centre for Automotive Technology, School of Applied Sciences, Cranfield University, \\ Bedfordshire, MK43 0AL, UK. \\ ${ }^{2}$ Department of Technology of Polymers, Cracow University of Technology, \\ 3155 Krakow, Poland \\ ${ }^{3}$ Grado Zero Espace Srl, Via Nove 2/a Montelupo F.no, Firenze, Tuscany 50056, Italy \\ *Corresponding Author Email:j.njuguna@.cranfield.ac.uk; Tel. +44 (0)1234754186
}

Abstract: Three-phase composites (thermoplastic polymer, glass-fibres and nanoparticles) were investigated as an alternative to two-phase (polymer and glass-fibres) composites. The effect of matrix and reinforcement material on the energy absorption capabilities of composite structures was studied in details in this paper. Dynamic and quasi-static axial collapse of conical structures was conducted using a high energy drop tower, as well as Instron universal testing machine. The impact event was recorded using a high-speed camera and the fracture surface was investigated with scanning electron microscopy (SEM). Attention was directed towards the relation between micro and macro fracture process with crack propagation mechanism and energy absorbed by the structure. The obtained results indicated an important influence of filler and matrix material on the energy absorption capabilities of the polymer composites. A significant increase in specific energy absorption (SEA) was observed in polyamide 6 (PA6) reinforced with nano-silica particles and glass-spheres, whereas addition of montmorillonite (MMT) caused a decrease in that property. On the other hand, very little influence of the secondary reinforcement on the energy absorption capabilities of polypropylene (PP) composites was found. 
Keywords: Nano-composites; Polymer-matrix composites; Short-fibre composites; Fracture; B. Impact behaviour;

\section{Introduction}

Modern vehicle structures must be able to withstand severe impact loads at the same time providing safety of the occupants. For the same reasons, structural materials used for crashworthy applications must be characterized by good energy absorption capability. In order to ensure survivability of an accident, structure has to dissipate energy in a controlled manner [1]. This is limited by two factors i.e. induced decelerations and maintenance of a survival space for occupants during a crash [2]. Traditionally metallic materials have been applied for crashworthy structures due to their ability to sustain plastic deformations. In contrast, polymer composite materials do not exhibit plastic deformations as they are usually brittle. However, if they are properly designed they can absorb high amounts of impact energy by progressive crashing and delamination [3].

Thermoplastic polymers, such as polypropylene (PP) and polyamide (PA), are widely used in the automotive industry because of their good mechanical performances, processing properties and low cost. However, their application as structural materials is limited due to their low impact resistance and energy absorption capabilities [4]. Incorporation of glass reinforcements and various nano-sized fillers such as: nanoparticles $\left(\mathrm{SiO}_{2}, \mathrm{TiO}_{2}, \mathrm{CaSiO}_{3}, \mathrm{Al}_{2} \mathrm{O}_{3}\right)$, carbon nano-tubes, and clay nano-plates; can be an appropriate solution to that problem $[5 ; 6]$. In case of light-weight structures, made of polymer composites, the most widely used nano-reinforcements are silica based particles, due to their good mechanical properties and high thermal stability $[7 ; 8]$. 
Numerous researches have been conducted to study the influence of nano-particles on the mechanical behaviour of polymer composites and main factors influencing their enhancing capabilities were outlined. This includes key parameters such as: shape [9] and size [10] of nano-fillers, matrix and reinforcement material [11-13], interfacial strength and interphase characteristics [14], as well as volume fraction [15] and quality of dispersion within the matrix [16].

For the purpose of measuring the energy absorption in composite structures, tube crashing experiments are the most prevailing. The ability of a composite structure to absorb the energy was found to be highly dependent on the mode of fracture. Materials which fail in a progressive manner, with extensive delamination and fragmentation, are able to absorb much higher energies than those materials which tend to fail in a brittle manner [17-20].

Regarding nanocomposite structures there is a lack of crash experiments conducted on these materials presented in the literature [5]. Energy absorption characteristics of nanocomposites have been mainly characterized by means of compression [21], flexural [22] and Charpy or Izod impact testing [23]. That is why the relation between mechanical properties of nanocomposite material and energy absorption characteristics of nanocomposite structure is not fully understood. To the best of our knowledge the present paper is a first report on the crashing behaviour of injection moulded, 3-phase (glass-fibres, nano fillers and polymer) composites, which could be applied in automotive structures. That is why it aims to correlate changes in the mechanical properties of the material with induced fracture modes and ability of the structure to crash progressively, after the addition of secondary reinforcement. 


\section{Experimental details}

\subsection{Materials and samples preparation}

Two types of matrices were utilised to prepare nano-reinforced materials: polypropylene (PP) Moplen HP500J from Basell Polyolefins and polyamide 6 (PA-6) Tarnamid T-30 from Zakłady Azotowe w Tarnowie-Mościcach, Poland. As a nanoreinforcement two different types of silica-particles $\left(\mathrm{SiO}_{2}\right)$ and montmorillonite (MMT) for both polar and apolar matrices were selected. This includes: organically modified MMT designed for nonpolar polyolefin matrices (Dellite $72 \mathrm{~T}$ from Laviosa); organically modified MMT designed for polar matrices (Dellite 43B from Laviosa); fumed silica with hydrophobic properties (surface modified with dichlorodimethyl silane (DCMS)) for nonpolar polyolefin matrices (AEROSIL 974 from Degussa) and fumed silica with hydrophilic properties for polar polymer (AEROSIL 200 from Degussa).

Four different glass-reinforced composite materials, supplied by MACOMASS Verkaufs AG Germany, were used to prepare nano and glass reinforced composite samples: glass-fibre reinforced polyamide (MM-PA I 1F30) and polypropylene (MMPP BI 24), as well as glass-spheres reinforced polyamide (MM-PA I 1K30) and polypropylene (MM-PP HE25).

Preparation of nano and glass reinforced polymer composites was conducted in three main steps: preparation of nano-composite granulate, mixing and extrusion of nano and glass reinforced composite granulate, and injection moulding of the structural cones. In the first step nano-reinforcement and polymeric matrix, all in solid (powder) form, were premixed before extrusion, in order to warrant the highest homogeneity of the composition. Subsequently, the premixed materials were fed into the twin-screw 
extruder. In the second step, nano-composite granulates and glass-fibre reinforced polymers were mixed in the extruder. As a result eight different composite materials were prepared as shown in Table 1. In the third step, crash cones were produced using injection moulding machine (Engel ES200/60 HL ST).

\subsection{Crash testing}

Quasi-static compression testing of the crash cones was carried out using Instron 5500R universal testing machine. Two set of samples of each material were tested at a crosshead speed of $0.1 \mathrm{~mm} / \mathrm{sec}$. The load was measured using $100 \mathrm{kN}$ load cell and the displacement was measured using a built in crosshead displacement sensor.

Impact tests of the crash cones were carried out on a high energy capacity drop tower. Three samples of each material were tested at the velocity of $6 \mathrm{~m} / \mathrm{s}$ corresponding to $2 \mathrm{~m}$ drop height. The tests were performed by direct impact of the falling beam. In order to ensure a good distribution of the load, $8 \mathrm{~mm}$ thick steel plate was placed on the top surface of the cone. The impactor mass of $54 \mathrm{~kg}$ was constant in all tests, giving the overall impact energy of $1050 \mathrm{~J}$ based on typical crash test in application of these components in rear crash elements in the vehicles. The load was measured using $200 \mathrm{kN}$ load cell, placed underneath the sample. In order to measure shortening of the sample (falling beam displacement), the linear variable differential transformer (LVDT) displacement transducer was used, with precision of $0.01 \mathrm{~mm}$ and maximum displacement speed of $10 \mathrm{~m} / \mathrm{s}$. The impact event was recorded using Phantom high speed camera. 


\section{Results and discussion}

\subsection{Crashing behaviour}

Crashing behaviour and energy absorption characteristic of the composite structures were studied by means of quasi-static compression and dynamic impact testing. From Figure 1 it can be seen that all PA composites and PPGF composite, tested under the quasi-static load, induce the secondary load-peaks bigger than the initial one. On the other hand, the same materials, tested under the dynamic conditions, induced significantly lower secondary load-peaks. These differences are associated with the mechanism of cracks propagation. If axial cracks are initiated at an early stage of the impact and propagate along the height of the cone (see Figure 2a), causing a weakening of the structure, then the load required to crash the sample can be smaller than that required to form these initial cracks. The opposite situation exists if plastic deformation is observed at the initial stage of the impact and it is followed by delamination and initiation of small local cracks (see Figure 2b). In such case, to provide a progression of the crash, the applied load must be similar or even higher than the initial peak.

\subsubsection{Failure modes}

The mechanism of crack initiation and propagation was found to have a strong impact on the failure mode induced in the structure. The difference in the failure modes was identified by the visual comparison of the crashed samples (see Figures 3 and 4), microscopic observation of the fracture surface (see Figures 5 and 6), as well as failure propagation visible on the high speed video records (example shown in Figure 2). As a 
result, the following fracture modes were identified and classified: Mode I - Progressive crashing with micro-fragmentation and delamination. This fracture mode corresponds to stable and progressive folding of the sample walls. The energy is dissipated throughout extensive delamination and debonding of the fibres. Local cracks are formed within the crushing zone and small fragments of the material become pushed inside or outside of the cone wall. This mode was observed in all PP materials tested under dynamic load (see Figure 3a-d), and it results in a very good energy absorption. Mode II - Brittle fracture with large fragmentation. This fracture mode corresponds to unstable and catastrophic failure of the sample. Its characteristic part is formation of large debris due to the propagation of axial cracks. These cracks become initiated at an early stage of the impact event and cause a significant decrease in post-failure strength and stability of the structure. Mode II indicates weak energy absorption and it was observed in PA/GF and PA/GF/MMT composites tested under the dynamic load (see Figure 3e and 3g). Mode III - Brittle fracture with progressive crashing and medium fragmentation. In this mode propagation of axial cracks, initiated at an early stage of the impact event, stops quickly after the formation. Therefore, the size of the generated debris is significantly smaller than the debris size observed in Mode II. Additionally, a delamination effect is observed, as a separation of the composite layers. That is why the structure does not suffer catastrophic failure, indicating relatively good energy absorption, compared to Mode II. This mode was observed in PA/GF/SiO 2 and PA/GF/GS composites tested under the dynamic load (see Figure $3 \mathrm{f}$ and $3 \mathrm{~h}$ ), as well as in all PA based materials and PP/GF composite tested under the quasi-static load (see Figure 4e-h and 4a). Mode IV Progressive folding with mushrooming effect. In this fracture mode a combination of plastic deformation and progressive crashing is observed. At an early stage of the crash, 
the structure is subjected to the plastic deformation, which is visible as a mushrooming effect. After the formation of the second fold, axial cracks are initiated leading to a splitting of the shell wall. The cracks are initiated by the radial stress, generated due to the expansion of the wall. This mode is observed in all PP based materials, with the secondary reinforcement, tested under the quasi-static load (see Figure 4b-d).

\subsection{Energy absorption}

To quantify the energy absorption capability of crashworthy structures the following parameters should be compared: total energy absorbed (E), specific energy absorption (SEA), mean crushing load and value of the initial load peak. However, the most important parameter, which makes possible a comparison of the energy absorption capability of different materials, is SEA. This parameter is defined as the amount of energy absorbed (area under the load-displacement curve) per unit mass of a crashed material, what means that it takes into account a crushing length of a sample. The energy absorption characteristics of all composites tested are listed in Tables 2 and 3.

Relating the energy absorption characteristic with the crashing characteristics, discussed in the previous chapter, it can be seen that the materials which failed in a progressive manner, with small local cracks induced (modes I and III), were able to absorb much higher energies than those with large continuous cracks (modes II and IV). This effect was caused by the fact that the fracture mode has a direct influence on the crushing parameters such as: crushing length, value of the peak loads and mean crashing load. It is generally observed that the crushing length of the structure increases if the large cracks and debris become initiated. Because of the same reason the post-failure strength of the material is also reduced, what can be recorded as a decrease in mean 
crushing load. That is why in the conducted experiments, the specific energy absorption of the material, which depends on these two parameters, was decreased in structures that failed in modes II and IV.

The previous studies on various composite materials, tested in the similar experiments [17-20], also show that the materials which fail with extensive delamination and fragmentation are able to absorb much higher energies than those which tend to fail in a brittle manner. That is why it can be concluded that the ability of a composite the structure to dissipate the impact energy is highly dependent on the mode of fracture.

\subsection{Effect of the matrix material on the mode of fracture}

The SEA parameter of all tested materials is compared on the bar charts presented in Figure 7. There is an important difference in energy absorption between the composites made of PP and PA6 matrices. All PP composites absorbed higher impact energy in relation to PA6 ones. In order to explain this phenomenon relation between the fracture mechanism and the mechanical properties of the matrix is outlined hereafter. All PP composites failed in a progressive and stable manner (fracture mode I), whereas in PA6 composites the failure was more unstable (fracture modes II and III). This was attributed to the mechanical properties of the matrix and fibre-matrix interaction. The mechanical properties of a matrix material such as: strength, stiffness and fracture toughness are well known to have a direct influence on the crashing behaviour of composite materials $[3 ; 12 ; 13]$. According to Farley [18], the energy absorption of the composites reinforced with ductile fibres is generally little affected by the matrix stiffness. 
However, if brittle fibres, such as glass fibres, are considered a change in the matrix stiffness can induce a significant change in the fracture mode.

The transition between the fracture modes due to the matrix material was detected at high speed video records by the observation of crack initiation and its propagation, as well as on the SEM pictures by the observation of the fracture surface. In case of the PP matrix, characterized by low strength and stiffness in relation to the PA6 matrix, the progressive crashing involves formation of small size fragments within the crush zone, which brake easily under the applied load. The cracks and failure are localized in a close proximity of the impact point and they are not propagating along the structure. Very little plastic deformation of the matrix is visible on the micrographs, as there are no characteristic deformation paths and fibrous texture of the material. Similarly as in the E- glass cloth composites studied by Hull [24], a high shear stress generated by the compressive force resulted in a mixture of fibre fracture debonding and interlaminar failure. This was induced by the weak matrix-fibre interphase, which was visible on the micrographs as a clean and smooth surface of the glass-fibres (see Figure 5). Delamination and debonding of the fibres increased the effectiveness of energy absorption at the same time not causing a weakening of the non-crashed section of the structure.

Contrary, PA6 based composites are characterized by strong bonding between the phases. This was visible on the SEM pictures as the fibres well embedded in the matrix, and bits of polymer bonded on the surface of the fibres (see Figure 6). The fracture was dominated by matrix and fibre cracking, whereas fibres pull out and debonding was of little meaning. The strong interpahse caused that the initiated shear forces did not induce debonding and interlaminar failure. As a result the applied load induced a significant 
radial stress leading to the expansion of the shell walls. This resulted in the initiation of severe axial cracks which reduced the energy absorption capability of the composite.

\subsection{Effect of the filler material}

Comparison of the SEA parameter due to the filler's material is shown in Figure 7. The secondary reinforcement had a negative influence on the impact behaviour of the PP composites both in the quasi-static and dynamic tests, reducing the value of the SEA parameter. This may be attributed to the properties of the PP material itself. Strong bonding between PP matrix and a reinforcement is difficult to achieve without an appropriate coupling agent, which assures a chemical coupling between non-polar polymer and polar reinforcement [25]. Another issue associated with the PP composites is a good dispersion of nano-reinforcement within a matrix. Mixing of untreated nanoreinforcement with the PP matrix, without a compatibilizer, can lead to a bad dispersion and existence of agglomeration regions, which additionally decrease the strength of the interphase region [26].

Regarding the PA6 composites, the SEA parameter increased in $\mathrm{SiO}_{2}$ and GS reinforced composites, whereas it decreased in MMT reinforced ones. The difference in energy absorption capability is associated with the change in material properties and fracture modes induced due to the secondary reinforcement. In PA/GF composite, the axial cracks were initiated at a relatively low load indicating low impact resistance of the material. The cracks propagated quickly along the height of the cone leading to the catastrophic failure of the structure (Mode II) and low energy absorption. Incorporation of $\mathrm{SiO}_{2}$ particles did not increase the impact strength of the material but it has changed its fracture behaviour. This was observed as a transition from fracture Mode II to Mode III. This change was caused by the significant reduction of the material brittleness, 
which was observed as an increase in elongation to break [27]. As a result, the strain induced in the structure did not initiate severe cracks as the material below the crush zone did not reach the failure strain. Moreover, an extensive delamination was observed increasing the energy absorption capability of the material.

These results are in line with other studies which report a significant increase in the ductility of the material after the addition of nano-particles $[10 ; 22 ; 28]$. However, as reported by several researchers $[10 ; 15 ; 29]$, the positive effect of particulate fillers can be gradually weaken with increasing filler content. This phenomenon is attributed to the stress concentration regions which may exist in the vicinity of the fillers with reduced interparticular distance or large size of the agglomerates [7]. Therefore, the bigger the interpartciulare distance and the smaller the size of the particles, the higher the toughness of the composite material.

The opposite behaviour was observed in PA/GF/MMT composite. In this case the impact strength of the material was increased but at the cost of reduced ductility. That is why the nano-composite became even more brittle than the neat PA/GF composite. Hence, the strain in radial direction reached the maximum allowable limit and the axial cracks propagated along the height of the structure, leading to a complete failure of the sample. As a result, the energy absorption capability of the material remained on the same level as the neat PA/GF, in spite of the increase in the impact resistance.

The biggest increase in the SEA parameter was found in PA/GF/GS composite. Similar to $\mathrm{SiO}_{2}$ reinforced $\mathrm{PA} / \mathrm{GF}$, the fracture mode has changed from Mode II to Mode III, after the addition of the secondary reinforcement, but the toughening mechanism was different. In this instance, the properties such as: stiffness, impact and tensile strength were improved, but with reduced elongation to brake, analogously to 
PA/GF/MMT composite. However, the increase in stiffness was much more significant, and additionally, the material was subjected to delamination effect. As a result, the

radial stress did not initiate any axial cracks, due to the high resistance of the material and propagation of the interlaminar cracks. That is why the crashing length of the cone was importantly reduced increasing the value of the SEA parameter.

Changes in the fracture modes between various PA composites were also clearly visible on the micoscale (see Figure 6). In neat $\mathrm{PA} / \mathrm{GF}$ and $\mathrm{PA} / \mathrm{GF} / \mathrm{SiO}_{2}$ composites the plastic deformation of the matrix was the most evident, whereas the fibres pull out and debonding was of little meaning. An extensive plastic deformation was clearly visible in $\mathrm{PA} / \mathrm{GF} / \mathrm{SiO}_{2}$ as a non-smooth texture and characteristic deformation paths. On the contrary, in $\mathrm{PA} / \mathrm{GF} / \mathrm{MMT}$ and $\mathrm{PA} / \mathrm{GF} / \mathrm{GS}$ composites, the plastic deformation of the matrix was reduced due to the transition to more brittle failure.

\subsection{Effect of the strain rate}

The effect of testing speed on the energy absorption capability of the polymer composites can be examined by the comparison of the results from static and dynamic crash tests, given in Figure 7. In the static test the energy absorption was the most effective in the PA composites, whereas in the dynamic test the effectiveness was significantly reduced. In addition, the weakening effect of the secondary reinforcement in the PP composite samples, tested under the quasi-static load, was much more evident than in the samples tested under the dynamic load. A similar trend was observed in the PA6 composites, in which the addition of secondary reinforcement resulted in reduction of the SEA parameter under the quasi-static load, whereas under the dynamic load the SEA parameter increased due to the secondary reinforcement. 
The reason for the large discrepancy in energy absorbed by the structures, tested under static and dynamic loads, is a strain rate sensitivity of polymeric materials. At low strain-rates a polymer is usually more ductile, weaker and less stiff as the molecular chains can reorganize and align with the slowly applied load. However, if the same load is applied at a high strain-rate the response of the material becomes more brittle, stiffer and the material gets stronger, as the molecular chains do not have enough time to reorganize [30]. Brittle reinforcements such as: glass fibres and silica, are generally insensitive to testing speed [31].

In the carried out experiments the transition from ductile to brittle behaviour was observed as a change in the energy absorption effectiveness. This phenomenon is associated with the decrease in fracture toughness and ductility of the matrix, caused by the increased testing speed. Low fracture toughness and ductility of the matrix corresponds to low resistance to the axial cracking of the shell walls and therefore, decreased energy absorption [32]. In brittle and stiff PA composites increase in brittleness, due to the high strain rate, caused a reduction of the strain limit, leading to the formation of severe cracks. Consequently, the fracture mode of the material has changed causing a significant decrease in energy absorption capability.

By contrast, increase in the testing speed of the PP composites caused an increase in energy absorption. As the PP material is characterized by low stiffness and strength, the structure indicated low resistance to the compressive load applied during the quasistatic test. This resulted in the formation of global cracks which were extending with the progressing compression, consequently leading to a decrease in energy absorption capability. At the high strain rates the PP composites became stiffer and stronger therefore, no global cracks were initiated. The fracture was localized within the crash 
zone and was dominated by delamination, debonding and fibre pullout effects. According to Jacob [33], the structural response and fracture mode at elevated strainrates is localized within the impact point, and therefore, properties of fibres and geometrical configuration of the structure is of little meaning. This causes that material which is able to fracture locally, and dissipate the energy by delamination, debonding and pull out effects, as observed in the PP composites, is able to absorb much higher impact energies.

\section{Conclusion}

Quasi-static and dynamic crashing behaviour of various polymer composites were studied in this paper. It has been proved that addition of secondary reinforcement into glass-fibre reinforced polymer composites can have a significant influence on the energy absorption capabilities of the material. The carried out experiments showed that by changing the matrix and the reinforcement material it is possible to change the micro-mechanism of a crash, and therefore, control the energy absorption characteristics of the composite. The following general remarks can be drawn, regarding the energy absorption of polymer composites: (i) Secondary reinforcement in PA composites leads to an increase in energy absorption capabilities of the structure. (ii) Energy absorption capabilities of PP composites have been decreased after the addition of secondary reinforcement. The possible reason of this phenomenon was bad dispersion of particles and week filler-matrix interphase. (iii) Mechanical and interphase properties of the matrix material had significant influence on the energy absorption capabilities of the composite. (iv) The transition from brittle to ductile fracture mode was clearly demonstrated as a main reason for the increased energy absorption capabilities. (v) Two 
different toughening mechanisms were observed. Firstly, due to the increase in elongation to brake, and secondly, due to the increase in the material impact strength and stiffness.

\section{Acknowledgments}

This work was funded by the European Commission (FP7 Project- CP-FP; Project Reference: 228536-2). The authors also gratefully acknowledge the EPSRC for testing equipment provided, as well as Grado Zero Espace SRL and Laviosa Chimica Mineraria SPA for the preparation of the materials.

\section{References}

[1] Njuguna, J. (2011), "The application of energy-absorbing structures on side impact protection systems", International Journal of Computer Applications in Technology, vol. 40, no. 4, pp. 280-287.

[2] Mamalis, A. G. (1998), Crashworthiness of composite thin-walled structural components, Technomic Pub. Co., Lancaster, Pa.

[3] Ramakrishna, S. (1997), "Microstructural design of composite materials for crashworthy structural applications", Materials \& Design, vol. 18, no. 3, pp. 167173.

[4] Yuan, Q. and Misra, R. (2006), "Impact fracture behavior of clay-reinforced polypropylene nanocomposites", Polymer, vol. 47, no. 12, pp. 4421-4433.

[5] Sun, L., Gibson, R. F., Gordaninejad, F. and Suhr, J. (2009), "Energy absorption capability of nanocomposites: A review", Composites Science and Technology, vol. 69 , no. 14 , pp. 2392-2409.

[6] Njuguna, J., Michałowski, S., Pielichowski, K., Kayvantash, K. and Walton, A. C. (2011), "Fabrication, characterization and low-velocity impact testing of hybrid sandwich composites with polyurethane/layered silicate foam cores", Polymer Composites, vol.32, no.1, pp.6-13 .

[7] Njuguna, J., Silva, F. and Sachse, S. (2011), "Nanocomposites for Vehicle Structural Applications", in Lin, T. (ed.) Nanofibers - Production, Properties and Functional Applications, InTech, pp. 401-434. 
[8] McWilliams, A. (2006), "Nanocomposites, nanoparticles, nanoclays, and nanotubes", NANO21C, BCC Research, Norwalk, CT, .

[9] Crosby, A. J. and Lee, J. Y. (2007), "Polymer nanocomposites: the "nano" effect on mechanical properties", Polymer reviews, vol. 47, no. 2, pp. 217-229.

[10] Fu, S. Y., Feng, X. Q., Lauke, B. and Mai, Y. W. (2008), "Effects of particle size, particle/matrix interface adhesion and particle loading on mechanical properties of particulate-polymer composites", Composites Part B: Engineering, vol. 39, no. 6, pp. 933-961.

[11] Sachse, S., Silva, F., Pielichowski, K., Leszczynska, A. and Njuguna, J. (2012), "Compression Strength and Low-Velocity Impact Performance of Nanocored Sandwich Composites", in A. J. M. Ferreira, E. Carrera (ed.), Mechanics of Nano, Micro and Macro Composite Structures , 18-20 June 2012, Politecnico di Torino, pp. 475.

[12] Lin, J. C. (2008), "Investigation of impact behavior of various silica-reinforced polymeric matrix nanocomposites", Composite Structures, vol. 84, no. 2, pp. 125131.

[13] Deshmane, C., Yuan, Q., Perkins, R. and Misra, R. (2007), "On striking variation in impact toughness of polyethylene-clay and polypropylene-clay nanocomposite systems: The effect of clay-polymer interaction", Materials Science and Engineering: A, vol. 458, no. 1-2, pp. 150-157.

[14] ZHANG, M., ZENG, H., ZHANG, L. and LIN, G. (1993), "Fracture characteristics of discontinuous carbon fibre-reinforced PPS and PES-C composites", Polymers \& Polymer Composites, vol. 1, no. 5, pp. 357-365.

[15] Zhang, H., Zhang, Z., Friedrich, K. and Eger, C. (2006), "Property improvements of in situ epoxy nanocomposites with reduced interparticle distance at high nanosilica content", Acta Materialia, vol. 54, no. 7, pp. 1833-1842.

[16] Wetzel, B., Haupert, F. and Qiu Zhang, M. (2003), "Epoxy nanocomposites with high mechanical and tribological performance", Composites Science and Technology, vol. 63, no. 14, pp. 2055-2067.

[17] Farley, G. L. (1991), "The effects of crushing speed on the energy-absorption capability of composite tubes", Journal of Composite Materials, vol. 25, no. 10, pp. 1314.

[18] Farley, G. L. (1987), "Energy absorption in composite materials for crashworthy structures", Sixth International Conference on Composite Materials and Second European Conference on Composite Materials(ICCM \& ECCM). Vol. 3, pp. 3.

[19] Mamalis, A., Manolakos, D., Ioannidis, M. and Papapostolou, D. (2005), "On the response of thin-walled CFRP composite tubular components subjected to static 
and dynamic axial compressive loading: experimental", Composite structures, vol. 69 , no. 4, pp. 407-420.

[20] Mamalis, A., Manolakos, D., Ioannidis, M. and Papapostolou, D. (2004), "Crashworthy characteristics of axially statically compressed thin-walled square CFRP composite tubes: experimental", Composite Structures, vol. 63, no. 3, pp. 347-360.

[21] Guo, Y. and Li, Y. (2007), "Quasi-static/dynamic response of SiO2-epoxy nanocomposites", Materials Science and Engineering: A, vol. 458, no. 1-2, pp. 330335.

[22] Han, J. and Cho, K. (2006), "Nanoparticle-induced enhancement in fracture toughness of highly loaded epoxy composites over a wide temperature range", Journal of Materials Science, vol. 41, no. 13, pp. 4239-4245.

[23] Viana, J. (2006), "Polymeric materials for impact and energy dissipation", Plastics, Rubber and Composites, 35, vol. 6, no. 7, pp. 260-267.

[24] Hull, D. (1991), "A unified approach to progressive crushing of fibre-reinforced composite tubes", Composites Science and Technology, vol. 40, no. 4, pp. 377-421.

[25] Maier, C. and Calafut, T. (1998), Polypropylene: the definitive user's guide and databook, William Andrew.

[26] Zoukrami, F., Haddaoui, N., Vanzeveren, C., Sclavons, M. and Devaux, J. (2008), "Effect of compatibilizer on the dispersion of untreated silica in a polypropylene matrix", Polymer International, vol. 57, no. 5, pp. 756-763.

[27] Silva, F., Sachse, S. and Njuguna, J. (2012), "Mechanical Properties and ImpactEnergy Absorption of Injection Moulded Nanocomposite Structures", 15th European Conference on Composite Materials (ECCM15), 24 - 28 June, Venice, .

[28] Ng, C., Schadler, L. and Siegel, R. (1999), "Synthesis and mechanical properties of TiO2-epoxy nanocomposites", Nanostructured Materials, vol. 12, no. 1-4, pp. 507-510.

[29] Unal, H., Findık, F. and Mimaroglu, A. (2003), "Mechanical behavior of nylon composites containing talc and kaolin", Journal of Applied Polymer Science, vol. 88, no. 7, pp. 1694-1697.

[30] Goble, D. and Wolff, E. (1993), "Strain-rate sensitivity index of thermoplastics", Journal of Materials Science, vol. 28, no. 22, pp. 5986-5994.

[31] Mamalis, A., Manolakos, D., Demosthenous, G. and Ioannidis, M. (1994), "Axial collapse of thin-walled fibreglass composite tubular components at elevated strain rates", Composites Engineering, vol. 4, no. 6, pp. 653-677. 
[32] Ramakrishna, S. (1995), "Energy absorption characteristics of knitted fabric reinforced epoxy composite tubes", Journal of Reinforced Plastics and Composites, vol. 14 , no. 10 , pp. 1121.

[33] Jacob, G. C., Fellers, J. F., Simunovic, S. and Starbuck, J. M. (2002), "Energy absorption in polymer composites for automotive crashworthiness", Journal of Composite Materials, vol. 36, no. 7, pp. 813. 


\section{Caption of Figures and Tables}

\section{Figure Captions}

Figure 1: load-displacement curves (a) static (b) dynamic

Figure 2: High speed camera records (a) PA/GF/MMT (b) $\mathrm{PA} / \mathrm{GF} / \mathrm{SiO}_{2}$

Figure 3: Dynamic collapse mode in: (a) PP/GF (b) PP/GF/SiO 2 (c) PP/GF/MMT (d) $\mathrm{PP} / \mathrm{GF} / \mathrm{GS}$ (e) PA/GF (f) PA/GF/SiO 2 (g) PA/GF/MMT (h) PA/GF/GS

Figure 4: Static collapse mode in: (a) $\mathrm{PP} / \mathrm{GF}$ (b) $\mathrm{PP} / \mathrm{GF} / \mathrm{SiO}_{2}$ (c) $\mathrm{PP} / \mathrm{GF} / \mathrm{MMT}$ (d) $\mathrm{PP} / \mathrm{GF} / \mathrm{GS}$ (e) PA/GF (f) PA/GF/SiO 2 (g) PA/GF/MMT (h) PA/GF/GS

Figure 5: SEM micrographs of PP composites: (a) neat, (b) $\mathrm{SiO}_{2}$, (C) MMT and (d) GS Figure 6: SEM micrographs of PA composites: (a) neat, (b) $\mathrm{SiO}_{2},(\mathrm{C}) \mathrm{MMT}$ and (d) GS Figure 7: Static and dynamic SEA parameter

\section{Table Captions}

Table 1: Manufactured composites

Table 2: Quasi-static crashing characteristics

Table 3: Dynamic crashing characteristics 
(a)
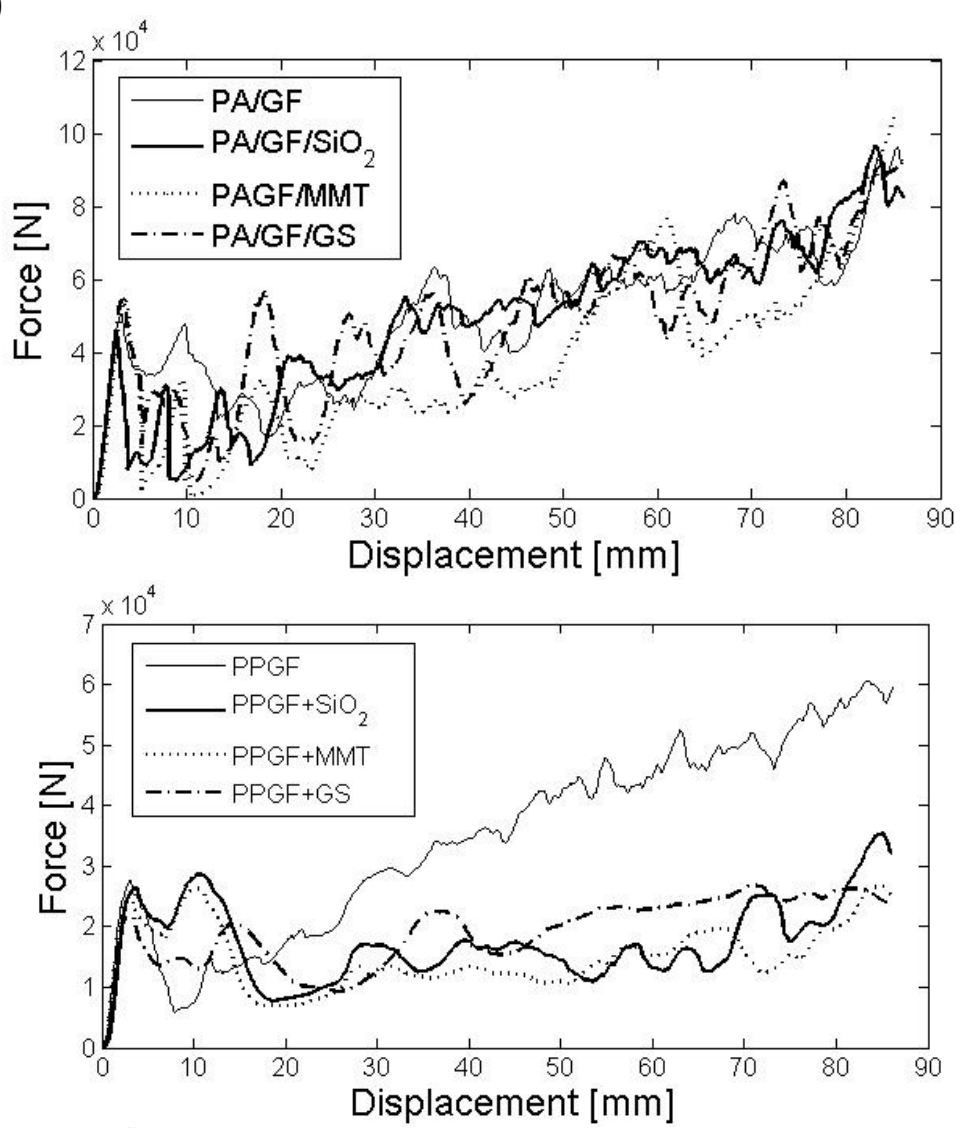

(b)
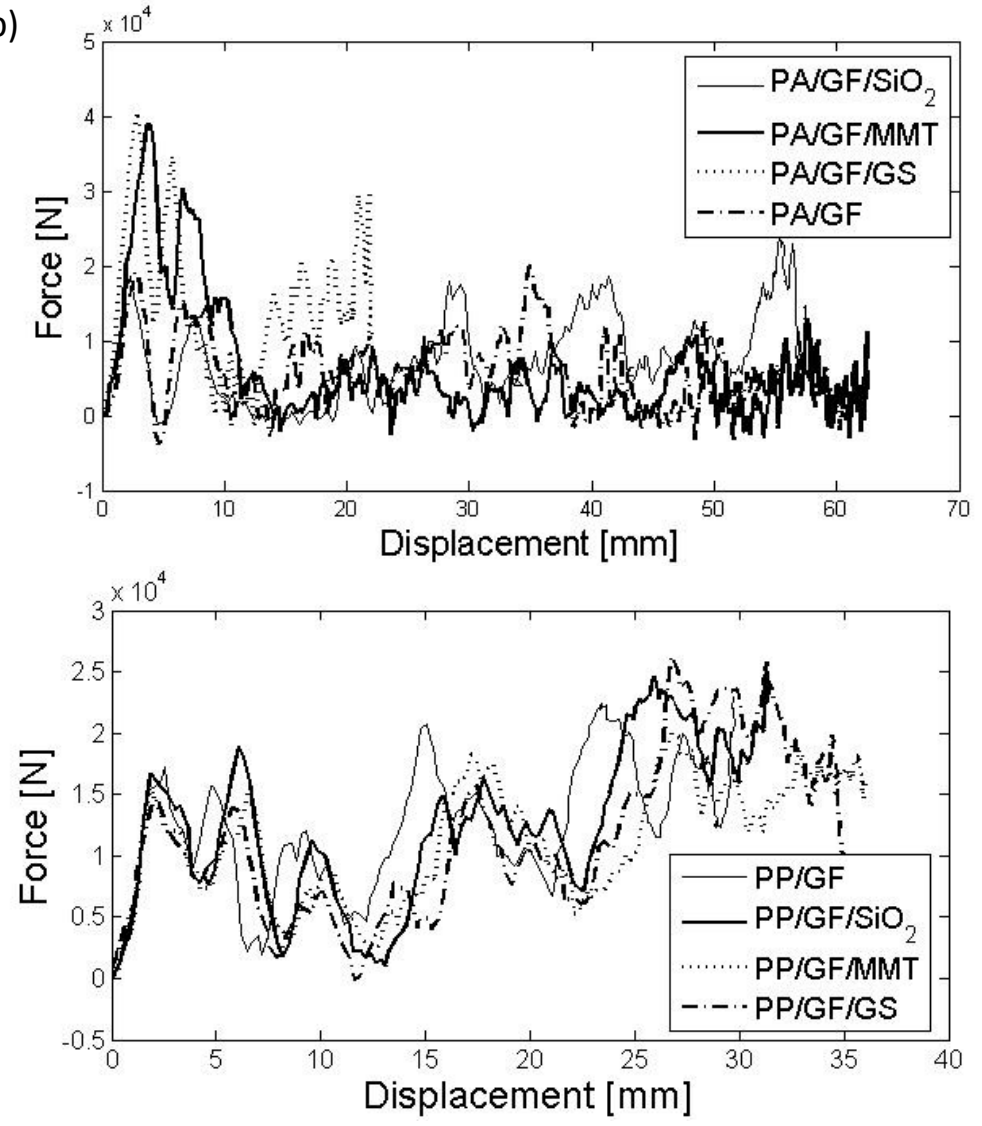

Figure 1: Load-displacement curves (a) static (b) dynamic 
(a)
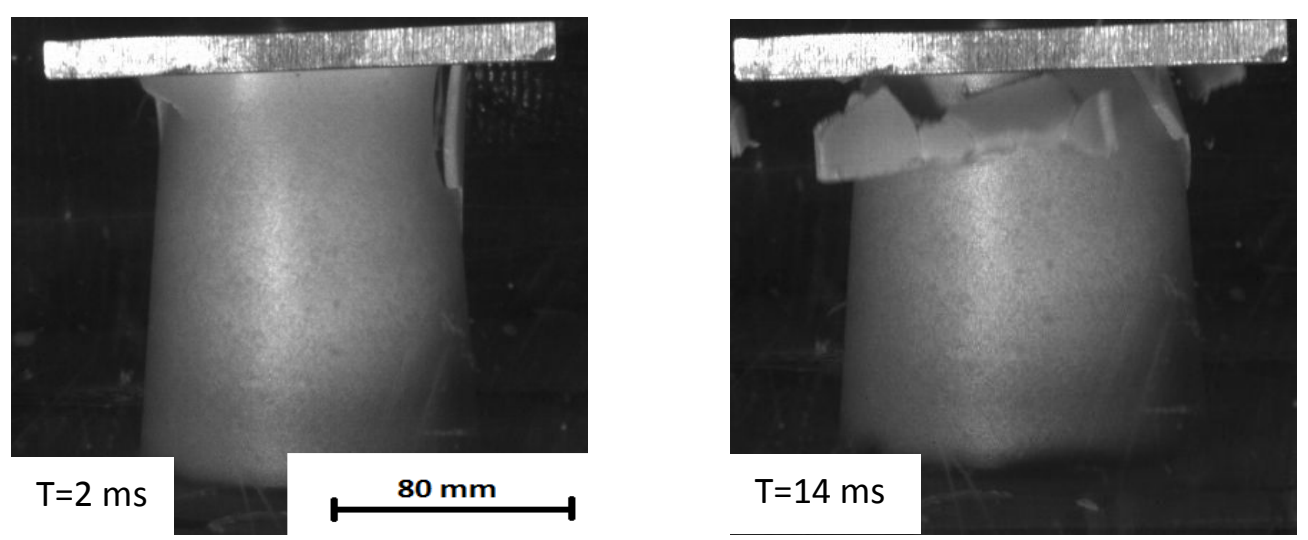

(b)
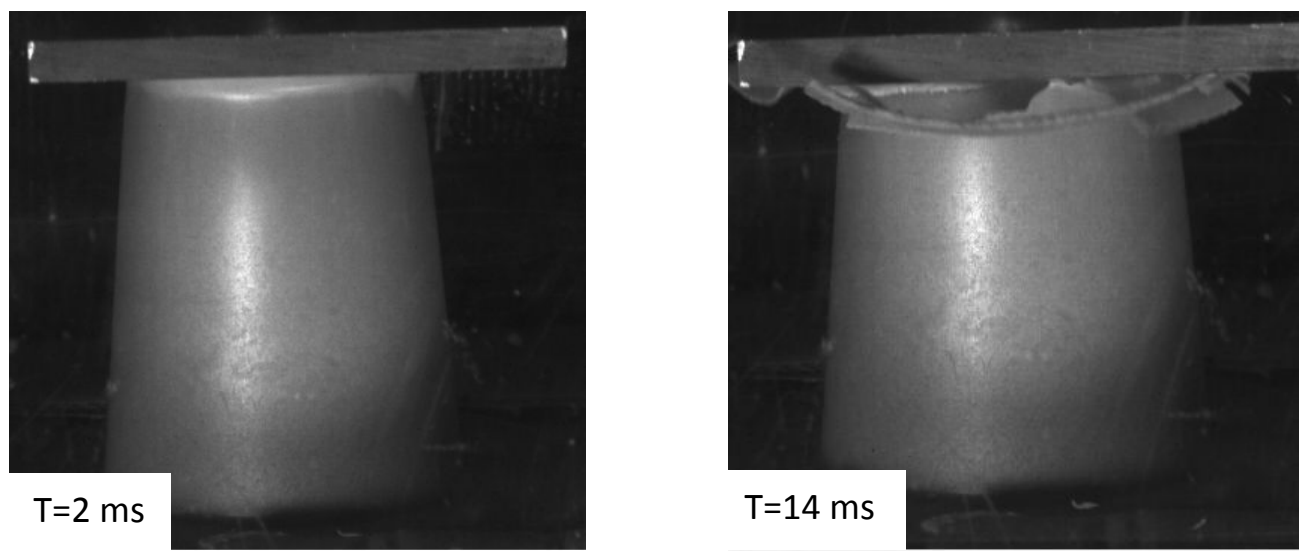

Figure 2: High speed camera records (a) PA/GF/MMT (b) $\mathrm{PA} / \mathrm{GF} / \mathrm{SiO}_{2}$ 
(a)

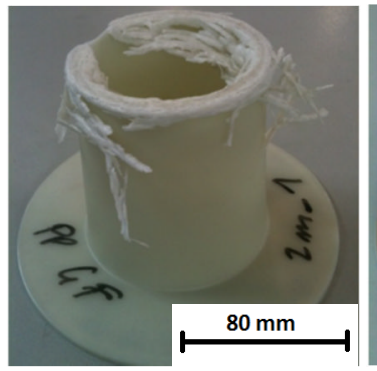

(e)

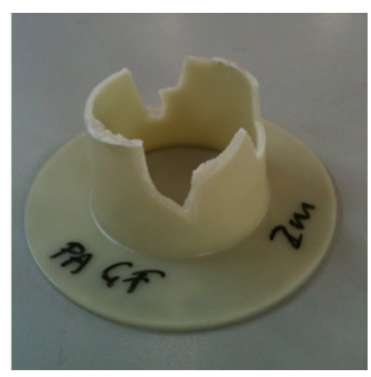

(b)

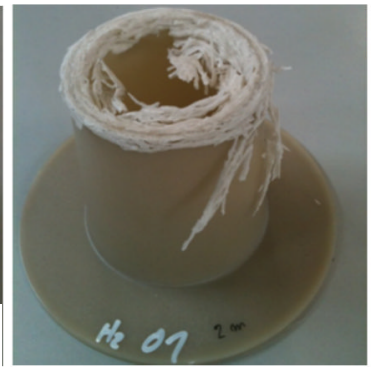

(f)

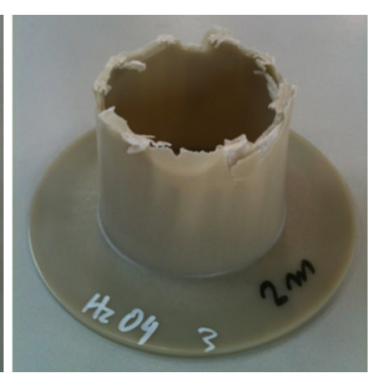

(c)

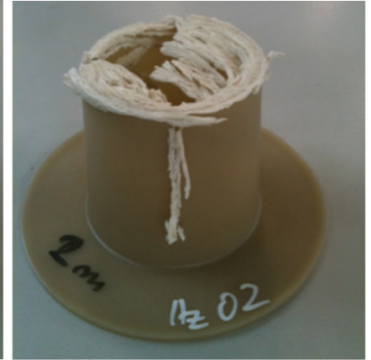

(g)

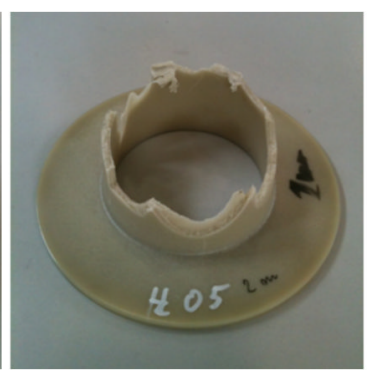

(d)

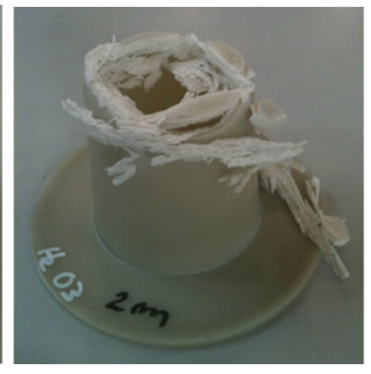

(h)

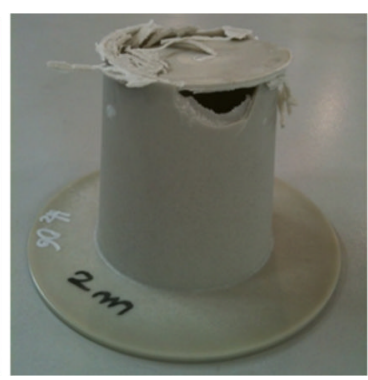

Figure 3: Dynamic collapse mode in: (a) PP/GF (b) PP/GF/SiO 2 (c) PP/GF/MMT (d) PP/GF/GS (e) PA/GF (f) PA/GF/SiO 2 (g) PA/GF/MMT (h) PA/GF/GS

(a)

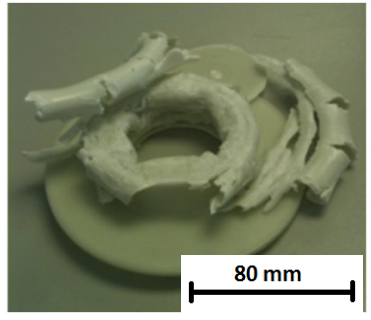

(e)

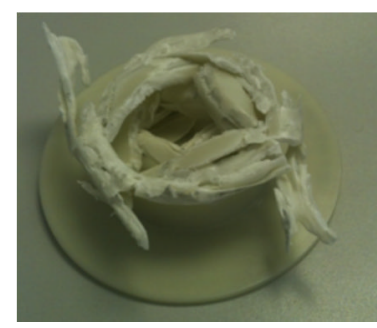

(b)

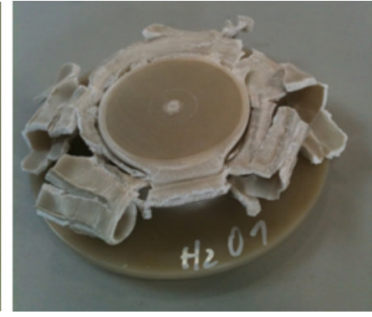

(f)

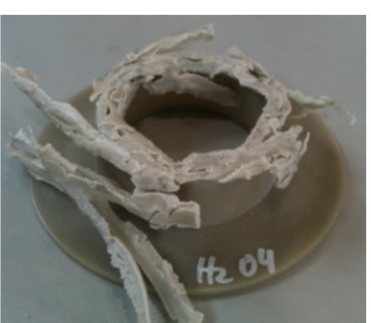

(c)

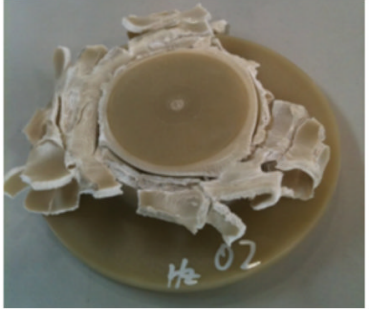

(g)

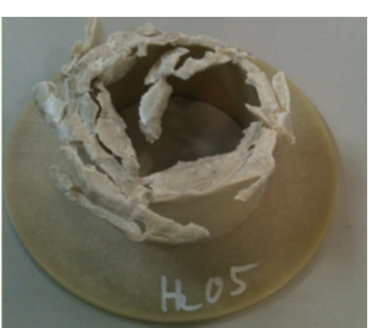

(d)

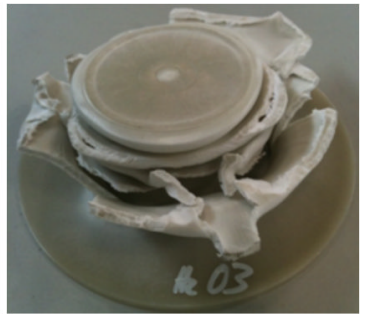

(h)

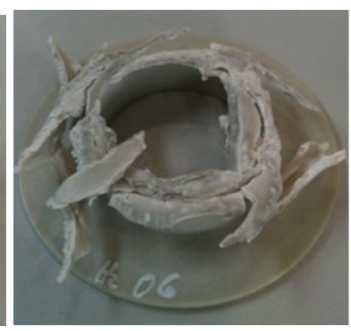

Figure 4: Static collapse mode in: (a) PP/GF (b) $\mathrm{PP} / \mathrm{GF} / \mathrm{SiO}_{2}$ (c) PP/GF/MMT (d) $\mathrm{PP} / \mathrm{GF} / \mathrm{GS}$ (e) PA/GF (f) PA/GF/SiO 2 (g) PA/GF/MMT (h) PA/GF/GS 
(a)

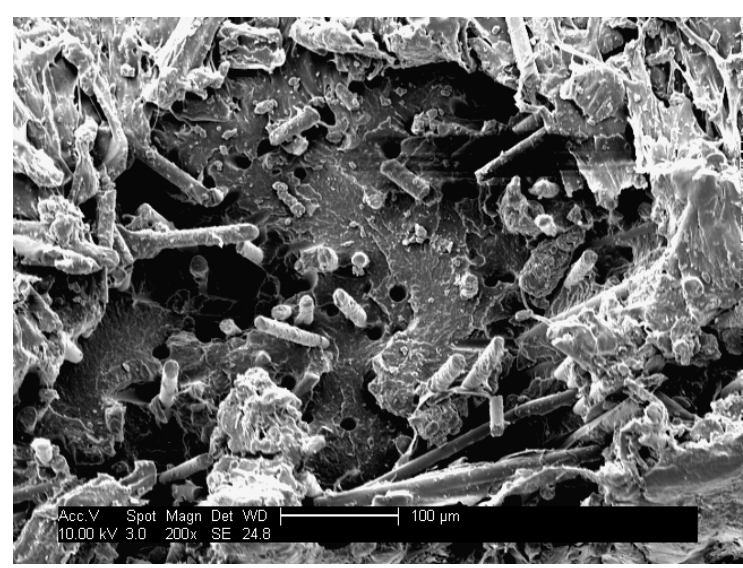

(c)

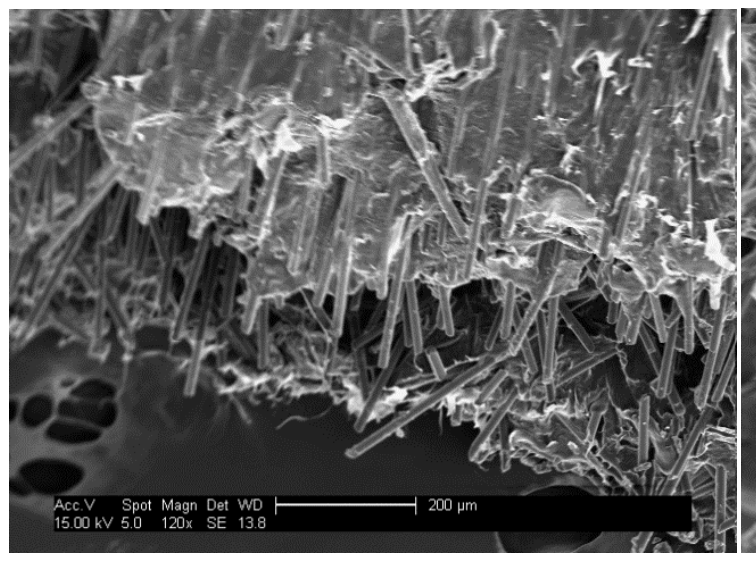

(d)

(b)
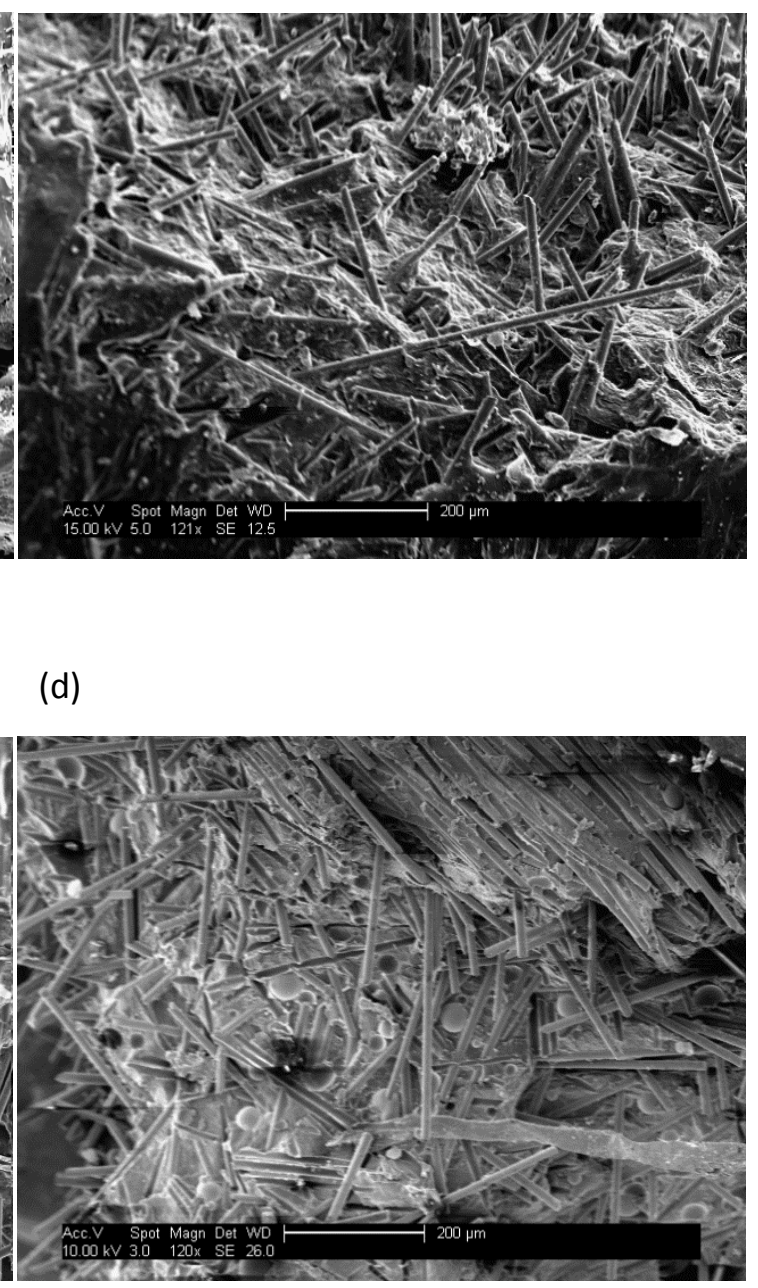

Figure 5: SEM micrographs of PP composites: (a) neat, (b) $\mathrm{SiO}_{2}$, (C) MMT and (d) GS 
(a)

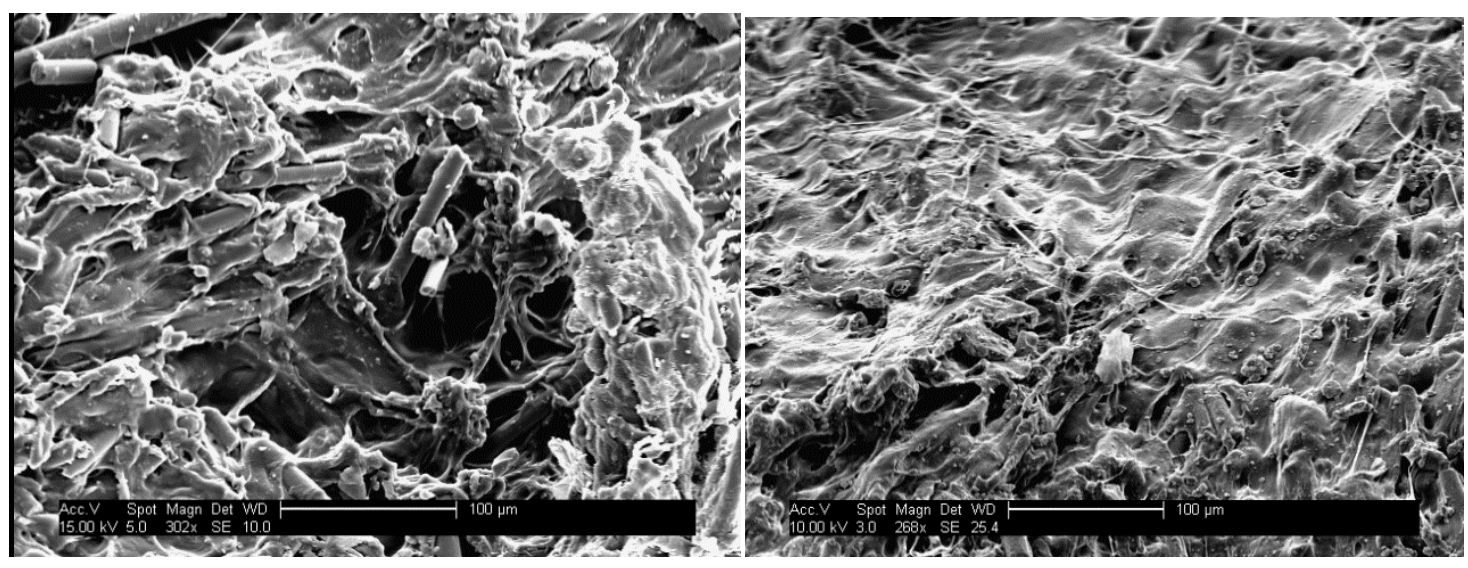

(c)

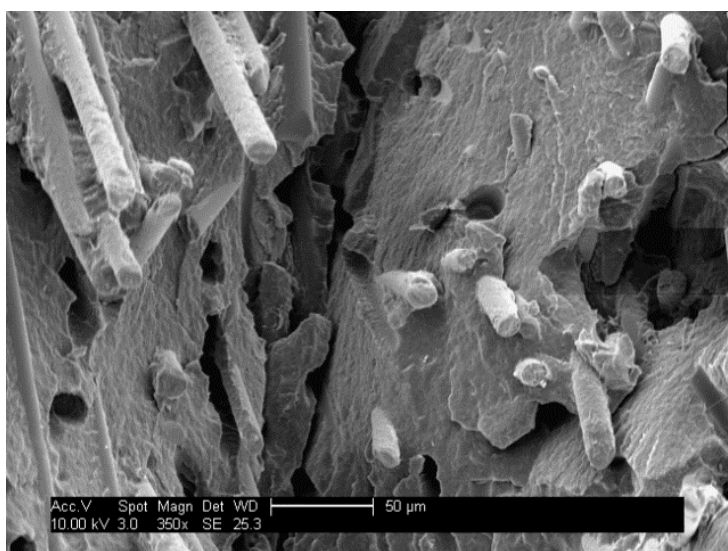

(d)

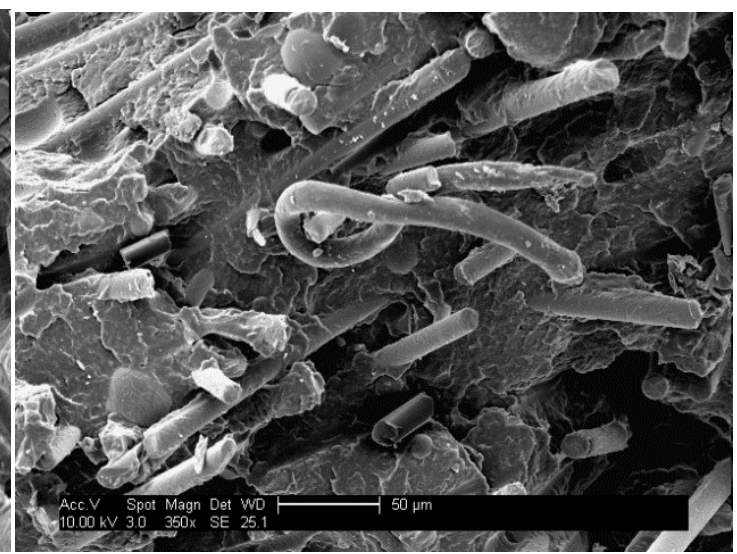

Figure 6: SEM micrographs of PA composites: (a) neat, (b) $\mathrm{SiO}_{2}$, (C) MMT and (d) GS
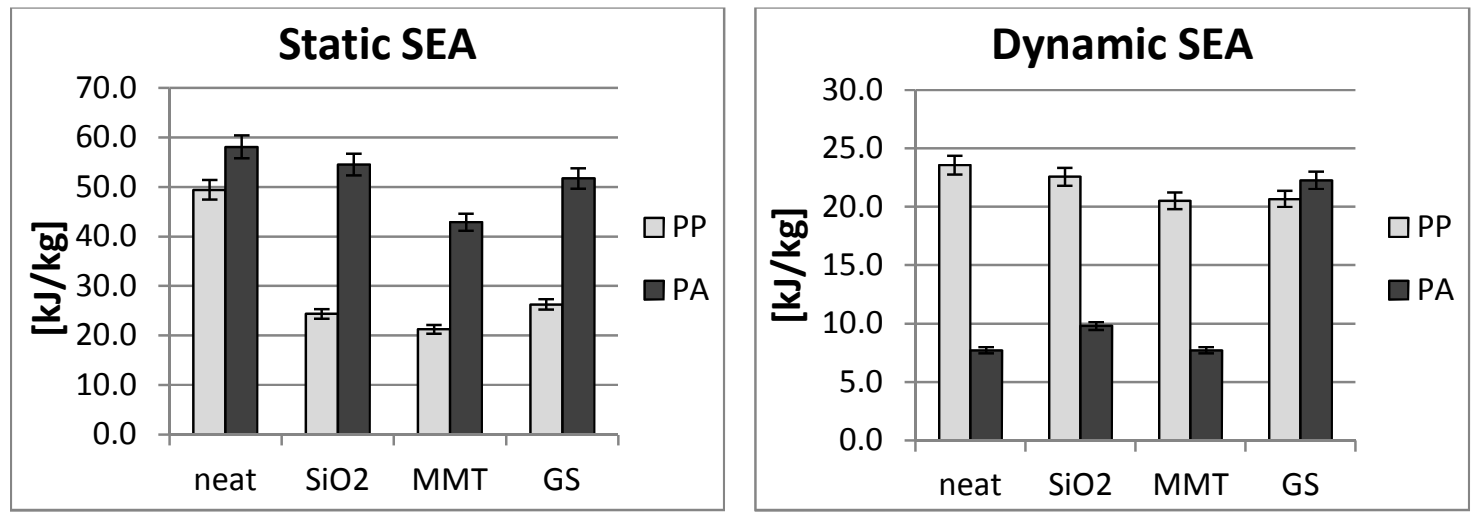

Figure 7: Static and dynamic SEA parameter 
Table1: Manufactured composites

PP composites

\begin{tabular}{|c|c|c|c|c|}
\hline Name & $\mathrm{PP} / \mathrm{GF}$ & $\mathrm{PP} / \mathrm{GF} / \mathrm{GS}$ & $\mathrm{PP} / \mathrm{GF} / \mathrm{SiO} 2$ & $\mathrm{PP} / \mathrm{GF} / \mathrm{MMT}$ \\
\hline Matrix & $\mathrm{PP}$ & $\mathrm{PP}$ & $\mathrm{PP}$ & $\mathrm{PP}$ \\
\hline $1^{\text {st }}$ filler $\left[w t^{0} \%\right]$ & GF $[30 \%]$ & GF [30\%] & GF $[30 \%]$ & GF $[30 \%]$ \\
\hline $2^{\text {nd }}$ filler $[\mathrm{wt} \%]$ & - & GS $[12 \%]$ & $\mathrm{SiO} 2[2 \%]$ & $\operatorname{MMT}[2 \%]$ \\
\hline \multicolumn{5}{|c|}{ PA6 composites } \\
\hline Name & $\mathrm{PA} / \mathrm{GF}$ & $\mathrm{PA} / \mathrm{GF} / \mathrm{GS}$ & $\mathrm{PA} / \mathrm{GF} / \mathrm{SiO} 2$ & $\mathrm{PA} / \mathrm{GF} / \mathrm{MMT}$ \\
\hline Matrix & PA & PA & PA & PA \\
\hline $1^{\text {st }}$ filler $[\mathrm{wt} \%]$ & GF [30\%] & GF [30\%] & GF [30\%] & GF [30\%] \\
\hline $2^{\text {nd }}$ filler $[\mathrm{wt} \%]$ & - & GS $[12 \%]$ & $\mathrm{SiO} 2[2 \%]$ & MMT [2\%] \\
\hline
\end{tabular}


Table 2: Quasi-static crashing characteristics

\begin{tabular}{lllllllc}
\hline Material & $\begin{array}{l}\text { Crash } \\
\text { length } \\
{[\mathrm{mm}]}\end{array}$ & $\begin{array}{l}\text { Collapse } \\
\text { mode }\end{array}$ & $\begin{array}{l}\text { Initial } \\
\text { peak } \\
{[\mathrm{kN}]}\end{array}$ & $\begin{array}{l}\text { Mean } \\
\text { crashing } \\
\text { load }[\mathrm{kN}]\end{array}$ & $\begin{array}{l}\text { Energy } \\
\text { absorbed } \\
{[\mathrm{kJ}]}\end{array}$ & $\begin{array}{l}\text { SEA } \\
{[\mathrm{kJ} / \mathrm{kg}]}\end{array}$ & $\begin{array}{l}\text { Change } \\
\text { in SEA } \\
{[\%]}\end{array}$ \\
\hline $\mathrm{PPGF}$ & 86 & III & 29.74 & 34.75 & 2.99 & 49.4 & - \\
$\mathrm{PPGF} / \mathrm{SiO}_{2}$ & 86 & IV & 26.59 & 17.86 & 1.48 & 24.4 & -50.7 \\
$\mathrm{PPGF} / \mathrm{MMT}$ & 86 & IV & 24.75 & 15.39 & 1.29 & 21.2 & -57.0 \\
$\mathrm{PPGF} / \mathrm{GS}$ & 86 & IV & 22.06 & 17.66 & 1.65 & 26.3 & -46.9 \\
\hline $\mathrm{PAGF}$ & 86 & III & 47.66 & 50.44 & 4.33 & 58.1 & - \\
$\mathrm{PAGF} / \mathrm{SiO}_{2}$ & 86 & III & 44.61 & 45.66 & 4.15 & 54.5 & -6.1 \\
$\mathrm{PAGF} / \mathrm{MMT}$ & 86 & III & 54.59 & 40.65 & 3.23 & 42.9 & -26.2 \\
$\mathrm{PAGF} / \mathrm{GS}$ & 86 & III & 55.10 & 45.74 & 4.11 & 51.7 & -11.0 \\
\hline
\end{tabular}


Table 3: Dynamic crashing characteristics

\begin{tabular}{lllllllc}
\hline Material & $\begin{array}{l}\text { Crash } \\
\text { length } \\
{[\mathrm{mm}]}\end{array}$ & $\begin{array}{l}\text { Collapse } \\
\text { mode }\end{array}$ & $\begin{array}{l}\text { Initial } \\
\text { peak } \\
{[\mathrm{kN}]}\end{array}$ & $\begin{array}{l}\text { Mean } \\
\text { crashing } \\
\text { load }[\mathrm{kN}]\end{array}$ & $\begin{array}{l}\text { Energy } \\
\text { absorbed } \\
{[\mathrm{kJ}]}\end{array}$ & $\begin{array}{l}\text { SEA } \\
{[\mathrm{kJ} / \mathrm{kg}]}\end{array}$ & $\begin{array}{l}\text { Change } \\
\text { in SEA } \\
{[\%]}\end{array}$ \\
\hline $\mathrm{PPGF}$ & 29.79 & I & 22.99 & 14.19 & 0.36 & 23.6 & - \\
$\mathrm{PPGF} / \mathrm{SiO}_{2}$ & 31.4 & I & 25.72 & 15.41 & 0.37 & 22.6 & -4.2 \\
$\mathrm{PPGF} / \mathrm{MMT}$ & 36.02 & I & 20.02 & 12.86 & 0.40 & 20.5 & -13.0 \\
$\mathrm{PPGF} / \mathrm{GS}$ & 35.03 & I & 26.28 & 13.52 & 0.40 & 20.7 & -12.3 \\
\hline $\mathrm{PAGF}$ & 60.5 & II & 19.99 & 5.64 & 0.35 & 7.7 & - \\
$\mathrm{PAGF} / \mathrm{SiO}_{2}$ & 57.56 & III & 26.51 & 8.98 & 0.43 & 9.8 & 27.0 \\
$\mathrm{PAGF} / \mathrm{MMT}$ & 62.61 & II & 38.82 & 4.48 & 0.37 & 7.7 & 0 \\
PAGF/GS & 22.03 & III & 40.42 & 15.58 & 0.32 & 22.3 & 188.5 \\
\hline
\end{tabular}

